\title{
Polypyrrole-derived Activated Carbons for High-performance Elec- trical Double-layer Capacitors with Ionic Liquid Electrolyte
}

\author{
Lu Wei, ${ }^{a, b}$ Marta Sevilla, ${ }^{c, d}$ Antonio B. Fuertes, ${ }^{d}$ Robert Mokaya, ${ }^{c, *}$ and Gleb Yushin ${ }^{a, *}$ \\ a School of Materials Science and Engineering, Georgia Institute of Technology, Atlanta, Georgia 30332, USA \\ ${ }^{\mathrm{b}}$ School of Materials Science and Engineering, Northwestern Polytechnical University, Xi'an, Shaanxi 710072, \\ China \\ ${ }^{c}$ School of Chemistry, University of Nottingham, University Park, Nottingham, NG7 2RD, U.K.

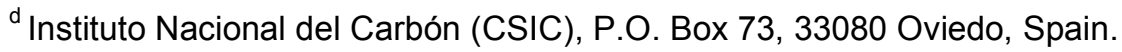

\begin{abstract}
*E-mail: yushin@gatech.edu (G. Yushin), r.mokaya@nottingham.ac.uk (R. Mokaya)
As electrical energy storage and delivery devices, carbon-based electrical double-layer capacitors (EDLCs) have attracted much attention for advancing the energy-efficient economy. Conventional methods for activated carbon (AC) synthesis offer limited control of their surface area and porosity, which results in a typical specific capacitance of $70-120 \mathrm{~F} \mathrm{~g}^{-1}$ in commercial EDLCs based on organic electrolytes and ionic liquids (ILs). Additionally, typical ACs produced from natural precursors suffer from the significant variation of their properties, which is detrimental for EDLC use in automotive applications. A novel method for AC synthesis for EDLCs is proposed. This method is based on direct activation of synthetic polymers. The proposed procedure allowed us to produce ACs with ultrahigh specific surface area of up to $3432 \mathrm{~m}^{2} \mathrm{~g}^{-1}$ and volume of $0.5-4 \mathrm{~nm}$ pores up to $2.39 \mathrm{~cm}^{3} \mathrm{~g}^{-1}$. The application of the produced carbons in EDLCs based on IL electrolyte showed specific capacitance approaching $300 \mathrm{~F} \mathrm{~g}^{-1}$, which is unprecedented for carbon materials, and 5-8\% performance improvement after 10000 charge-discharge cycles at the very high current density of $10 \mathrm{~A} \mathrm{~g}^{-1}$. The remarkable characteristics of the produced materials and the capability of the fabricated EDLCs to operate safely in a wide electrochemical window at elevated temperatures, suggest that the proposed synthesis route offers excellent potential for large-scale material production for EDLC use in electric vehicles and industrial applications.
\end{abstract}

\section{INTRODUCTION}

Electrical double-layer capacitors (EDLCs) are a unique type of high-power electrochemical energy storage devices, where the capacitance arises from the charge separation at an electrode-electrolyte interface. ${ }^{[1]}$ Recently, EDLCs have attracted considerable attention because of their high power density, sub-second charging and ultra-long cycle life, which make them attractive for a wide range of applications, including consumer electronics, uninterruptable power sources, energy efficient industrial equipment, power grid systems and most importantly hybrid electric vehicles. ${ }^{[2-8]}$

The energy storage in EDLC is based on the adsorption of electrolyte ions on the large specific surface area of electrically conductive porous electrodes, most commonly porous carbons. Several promising methods have been explored for porous carbon synthesis for industrial EDLC applications. For example, the zeolite-templated carbons studied by Kyotani ${ }^{[9]}$ and later by other groups ${ }^{[10-13]}$ allow formation of uniform microporous carbons with high specific capacitance of 90-150 $\mathrm{F} \mathrm{g} \mathrm{g}^{-1}$ in organic electrolytes. However, the current need to use dangerous hydrofluoric (HF) acid for efficient template dissolution, has so far prevented commercial applications of this technology. Selective etching of metals from metal carbides offer controlled pore size distribution in the produced carbidederived carbons (CDCs). ${ }^{[14-16]}$ Specific capacitance of 70-170
$\mathrm{F} \mathrm{g}^{-1}$ was demonstrated in organic electrolytes and ionic liquids, ${ }^{[5,17-19]}$ but the material commonly suffers from tortuous pore shape, unless CDCs are produced with the help of ordered silica templates. ${ }^{[20,21}$ Exfoliation of graphite with subsequent activation is yet another interesting approach for porous carbon formation, which was recently demonstrated to offer impressive capacitance of up to $167 \mathrm{~F} \mathrm{~g} \mathrm{~g}^{-1}$ in ionic liquid/organic solvent mixture. ${ }^{[7]}$ However, poor control over the pore size distribution (PSD) and formation of significant content of large mesopores in this carbon limit its volumetric capacitance. Furthermore, as shown by prior studies ${ }^{[5,22]}$ the specific capacitance in small microporous pores, where the ion solvation shell becomes highly distorted, ${ }^{[5,23,24]}$ could be larger than in mesopores. Strictly mesoporous carbons, such as carbon onions and carbon nanotubes ${ }^{[3,25]}$ may find applications when ultra-fast rate capability is needed. However, their limited surface area and excessive porosity minimizes the energy density of the fabricated devices.

High surface area activated carbons (ACs) are predominant electrode materials for commercial EDLCs due to their well developed manufacturing technologies, easy production of large quantities, relatively low cost and great cycle stability. While commercial ACs exhibit only moderately high specific capacitance (commonly $70-120 \mathrm{~F} \mathrm{~g}^{-1}$ in organic electrolytes) $[2,26-28]$ the recent developments in their synthesis ${ }^{29-33}$ demonstrate that for the significant portion of the EDLC applications 
ACs will likely remain the material of choice, in spite of the alternative structures introduced ${ }^{2-13,18-21,25}$. Therefore, novel methods of AC synthesis with well controlled properties, high volume of micropores and better capacitive characteristics are of the highest demand for further development of EDLC technology. In our recent paper we utilized an environmentally friendly low-temperature hydrothermal carbonization ${ }^{34-37}$ followed by activation to transform natural organic materials into ACs with well developed porosity (surfaced area of 2100$\left.2450 \mathrm{~m}^{2} \mathrm{~g}^{-1}\right)$ and very high capacitance $\left(140-210 \mathrm{~F} \mathrm{~g}^{-1}\right)$ in organic electrolytes ${ }^{32}$. The serious disadvantage of natural organic precursors (such as wood, seaweed, coconut shells and others), however, is the lack of sufficient uniformity and consistency in their properties, which could be prohibitive for automotive applications of EDLCs. Furthermore, the use of flammable organic solvents in EDLCs raises many safety concerns. In contrast, ionic liquids (ILs) electrolytes offer greatly enhanced operation safety, higher voltage stability (and thus higher energy density) and longer lifetime to EDLCs ${ }^{18,38-}$

Here, we report for the first time on the preparation of ACs from synthetic polymers by a one-step chemical activation processs with $\mathrm{KOH}$. For the proof-of-concept studies we selected polypyrrole (PPy) as synthetic precursor material due to a high percentage of carbonaceous residue left after thermal treatment. We demonstrate that PPy could be transformed to highly porous carbons with BET ${ }^{[42]}$ specific surface area (SSA) of up to $3432 \mathrm{~m}^{2} \mathrm{~g}^{-1}$, one of the highest values ever reported for carbon materials. ${ }^{[7]}$ We further demonstrate that PPy-derived AC offer truly outstanding specific capacitance approaching $\approx 300 \mathrm{~F} \mathrm{~g} \mathrm{~g}^{-1}$ in 1-ethyl-3-methylimidazolium tetrafluoroborate (EMImBF4) electrolyte at $60{ }^{\circ} \mathrm{C}$. These values are 100 to $300 \%$ higher than specific capacitance reported in commercial ACs, CDC, carbon nanotubes (CNT), and graphene, thus representing a significant technological breakthrough enabled by the proposed chemical synthesis route.

\section{RESULTS AND DISCUSSION}

The carbon formation procedure employed in our study involved the room temperature synthesis of the polymer polypyrrole from an aqueous suspension of pyrrole and ferric chloride solution. The resulting polypyrrole had a carbon content (wt $\%$ ) of 65 with $16.6,13.5$ and 4.5 of oxygen, nitrogen and hydrogen respectively (Table S1, Supporting Information). The AC preparation procedure performed at $600-700{ }^{\circ} \mathrm{C}$ utilizes these uniformly distributed hetero atoms (primarily $\mathrm{O}$ and $\mathrm{N}$ ) to transform the polypyrrole into highly porous carbons with tunable elemental composition and interconnected pore network. The produced carbons were crushed into finer powders and labeled according to their activation temperature as AC-P600, AC-P650, and AC-P700.

The produced ACs are made up of irregularly shaped platelets $20-50 \mu \mathrm{m}$ in lateral dimensions and $5-10 \mu \mathrm{m}$ in thickness, with sharp corners and "swiss cheese"-like macropores of 5 $\mu \mathrm{m}$ in diameter, originating from the gas bubble formation during the activation (Figure 1a). The activation changed the original aerogel-like structure of the polypyrrole precursor (Figure S1, Supporting Information) completely.
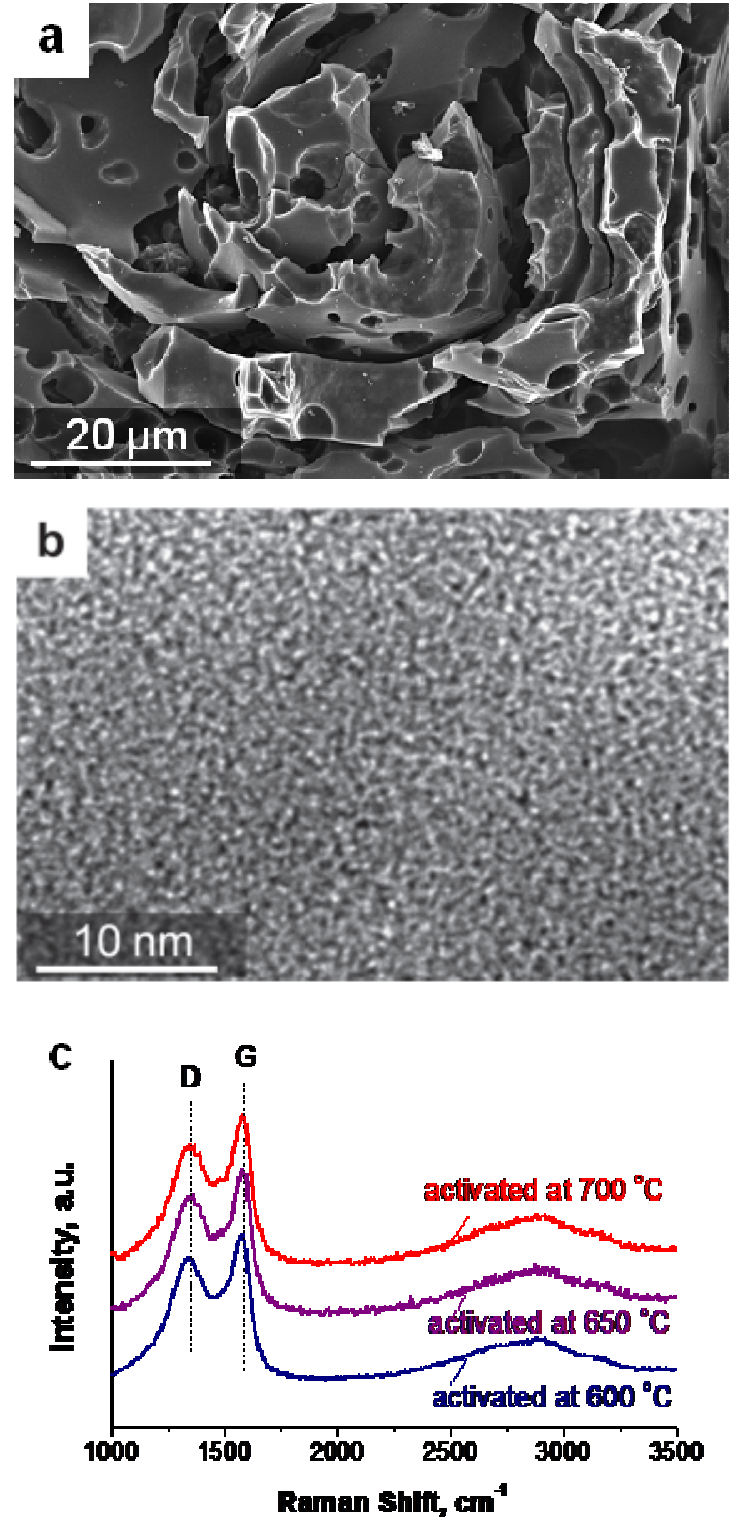

Figure 1. Structure of polypyrrole-derived activated materials: a) Scanning electron microscopy (SEM) and b) TEM images of the carbon activated at $700{ }^{\circ} \mathrm{C}$ and c) Raman spectra of samples activated at different temperatures.

High-resolution transmission electron microscopy (TEM) revealed highly disordered porous carbon structure without graphite ribbons and crystalline impurities (Figure 1b). Raman spectroscopy studies similarly showed spectra characteristic for highly disordered carbons ${ }^{[10,20,21,43]}$ (Figure 1c). In the spectral range from 0 to $2000 \mathrm{~cm}^{-1}$ a perfect graphite shows only one narrow Raman active mode, the G-band, at $1582 \mathrm{~cm}^{-1}$ and corresponding to graphite in-plane vibrations. ${ }^{[44-46]}$ Disordered carbons additionally show the D band at $\sim 1350 \mathrm{~cm}^{-1}$. This band is associated with a double-resonance Raman process in disordered carbon, ${ }^{[46,47]}$ when any phonon mode irrespective of the symmetry can give rise to this peak if the wave vector of the phonon is twice as large as the wave vector of the electronic transition excited by the incident phonon. The large value of the full width at half maximum (FWHM) of D and G bands ( $\sim 190$ and $90 \mathrm{~cm}^{-1}$, respectively, for all samples) and a 
high value of the ratio of integrated intensities of these peaks $\left(\mathrm{I}_{\mathrm{D}} / \mathrm{I}_{\mathrm{G}}=1.8\right)$ is typical for porous carbons with very high degree of structural (i.e, graphitic) disorder. ${ }^{[10,20,21,43]}$ The lack of the sharp and strong peaks in the spectral range $2400-3300 \mathrm{~cm}^{-1}$ $\left(2 \mathrm{D}, \mathrm{D}+\mathrm{G}, \mathrm{T}+\mathrm{D}, \mathrm{T}+\mathrm{G}, 2 \mathrm{D}\right.$ ' and other bands) ${ }^{[46]}$ similarly suggest the lack of graphitic ribbon structures in the sample, ${ }^{[46]}$ confirming the XRD measurements (Figure 1b).

The nitrogen sorption isotherms of the ACs (Figure 2a) showed significant impact of the activation temperature on their porosity. The AC-P600 sample activated at the lowest temperature of $600{ }^{\circ} \mathrm{C}$ exhibits a type-I sorption isotherm (in the the Brunauer classification) ${ }^{[42]}$ with saturation at a relative pressure $\left(\mathrm{P} / \mathrm{P}_{0}\right)$ of ca. 0.2 , characteristic for microporous materials with very low volume of pores $>2 \mathrm{~nm}$. The total amount of $\mathrm{N}_{2}$ adsorbed at $\mathrm{P} / \mathrm{P}_{0} \sim 0.99$ is $\sim 670 \mathrm{~cm}^{3} \mathrm{~g}^{-1}$, which corresponds to the moderately high pore volume of $1.1 \mathrm{~cm}^{3} \mathrm{~g}^{-1}$. As the activation temperature increases to 650 and $700{ }^{\circ} \mathrm{C}$ the pore volume doubles and the isotherms change to a type-IV with a significant slope at higher relative pressures, commonly associated with capillary condensation in small mesopores. The total BET (Brunauer Emmett Teller) ${ }^{[42]}$ SSA (specific surface area) of the carbons increases with activation temperature from 2095 to 3246 and to $3432 \mathrm{~m}^{2} \mathrm{~g}^{-1}$. These surface areas are higher than those of porous carbons produced by activation of graphene, ${ }^{[7]}$ higher than theoretical surface area of graphene $\left(2630 \mathrm{~m}^{2} \mathrm{~g}^{-1}\right)$ and over 7 times higher than that of porous carbons hydrothermally synthesized with the assistance of sacrificial templates reported previously. ${ }^{[48]}$ This high surface areas likely result from the formation of multiple defects (holes) in the individual graphene layers of the produced carbons, which lead to a larger number of surface sites available for $\mathrm{N}_{2}$ adsorption. According to non-local density functional theory (NLDFT) calculations, sample AC-P600 contained virtually no pores larger than $3 \mathrm{~nm}$ (Figure $2 \mathrm{~b}, \mathrm{c}$ ). However, activation at higher temperatures of 650 and $700{ }^{\circ} \mathrm{C}$ leads to the noticeable increase in the volume of small mesopores in the range of $2-4 \mathrm{~nm}$. Table 1 summarizes the porosity characteristics of our samples. The difference in absolute values between BET and NLDFT SSA (Table 1) is commonly observed and is expected as the calculations are based on different assumptions. ${ }^{[20,42]}$

Following Kurig et al. ${ }^{[40]}$ and our prior work ${ }^{[20,41]}$ we selected $\mathrm{EMImBF}_{4}$ as a very promising IL electrolyte. Specific capacitance of the produced carbon samples was estimated using cyclic voltammetry $(\mathrm{C}-\mathrm{V})$ at different scan rates (Figure 3$)$. At low scan rate of $1 \mathrm{mV} \mathrm{s}^{-1}$, the $\mathrm{C}-\mathrm{V}$ curves show quasirectangular shape even at room temperature, which is characteristic for an ideal EDLC with little electrolyte diffusion limitations. The pseudocapacitance peaks visible at $\sim 1.2 \mathrm{~V}$ in the symmetrical EDLC may result either from impurities present in the IL or from the reaction of the IL with the functional groups on the carbon surface. Importantly for practical applications, the Faradaic reactions present did not negatively affect the cycle stability of the assembled EDLC. As the sweep rate increased to $100 \mathrm{mV} \mathrm{s}^{-1}$ the pseudocapacitance peaks disappeared (Figure $3 \mathrm{a}, \mathrm{b}$ ) but the shape of the $\mathrm{C}-\mathrm{V}$ curves retained nearly rectangular shape, particularly when measured at $60{ }^{\circ} \mathrm{C}$ on samples activated at 650 and $700{ }^{\circ} \mathrm{C}$ (Figure 3b). Within the $20-60{ }^{\circ} \mathrm{C}$ measurement temperature range samples AC-P650 and AC-P700 retained up to $60 \%$ of the maximum specific capacitance when the sweep rate was increased from 1 to $100 \mathrm{mV} \mathrm{s}^{-1}$ (Figure 3c, d). The decrease in capacitance at higher rates is common for activated carbons and originates from the insufficient time available for ion diffusion and adsorption inside the smallest inner pores within the carbon particles. Considering the large $(\sim 300 \mu \mathrm{m})$ electrode thickness and very large (un-optimized) particle size (Figure 1a) the $60 \%$ capacitance retention demonstrated a very good promise of the synthesized materials for high-power applications. Note that particle size reduction to sub-micron range ${ }^{19}$ should result in the sufficient (10-fold or more) decrease in the diffusion length $\ell_{d}$ for ions accessing the inner core of the carbon particles surface through the network of 0.5-4 nm pores (Figure 2 $\mathrm{b}, \mathrm{c})$, which, in turn, should significantly reduce the characteristic charging time $\left(\tau \propto \ell_{d}^{2}\right)$ and dramatically improve the EDLC power characteristics.
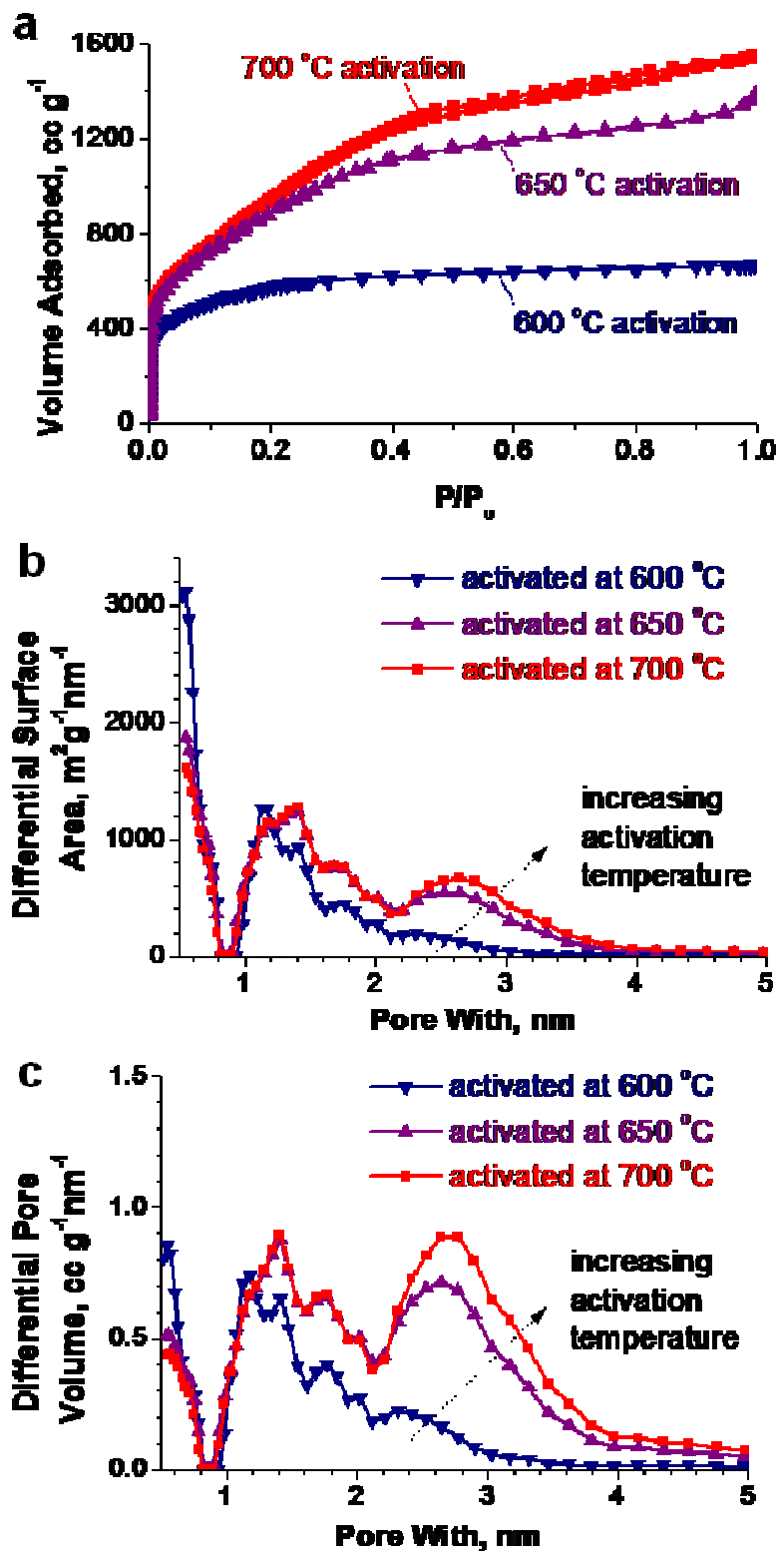

Figure 2. Porosity characterization: a) N2 gas adsorption isotherms and b,c) NL-DFT pore size distribution of polypyrrolederived ACs. 
Table 1. Porosity properties of the polypyrrole-derived activated carbon materials

\begin{tabular}{cccccc}
\hline Sample & $\begin{array}{c}\text { BET-SSA } \\
\left(\mathrm{m}^{2} \mathrm{~g}^{-1}\right)\end{array}$ & $\begin{array}{c}\text { DFT-SSA } \\
\left(\mathrm{m}^{2} \mathrm{~g}^{-1}\right)\end{array}$ & $\begin{array}{c}\text { MP-SSA } \\
\left(\mathrm{m}^{2} \mathrm{~g}^{-1}\right)\end{array}$ & $\begin{array}{c}\text { MPV } \\
\left(\mathrm{cm}^{3} \mathrm{~g}^{-1}\right)\end{array}$ & $\begin{array}{c}\text { TPV } \\
\left(\mathrm{cm}^{3} \mathrm{~g}^{-1}\right)\end{array}$ \\
\hline AC-P600 (Activated at $\left.600^{\circ} \mathrm{C}\right)$ & 2095 & 1703 & 1550 & 0.71 & 1.10 \\
AC-P650 (Activated at $\left.650^{\circ} \mathrm{C}\right)$ & 3246 & 2160 & 1520 & 0.84 & 2.13 \\
AC-P700 (Activated at $\left.700^{\circ} \mathrm{C}\right)$ & 3432 & 2244 & 1429 & 0.81 & 2.39
\end{tabular}

[a] BET Specific Surface Area measured for $\mathrm{P} / \mathrm{P}_{0}=0.06-0.14$, [b] NL DFT Specific Surface Area, [c] NL DFT Specific Surface Area of Micropores (pores $<2 \mathrm{~nm}$ ), [d] NL-DFT Micropore Volume, [e] Total Pore Volume measured at $\mathrm{P} / \mathrm{P}_{0}=0.994$.

a

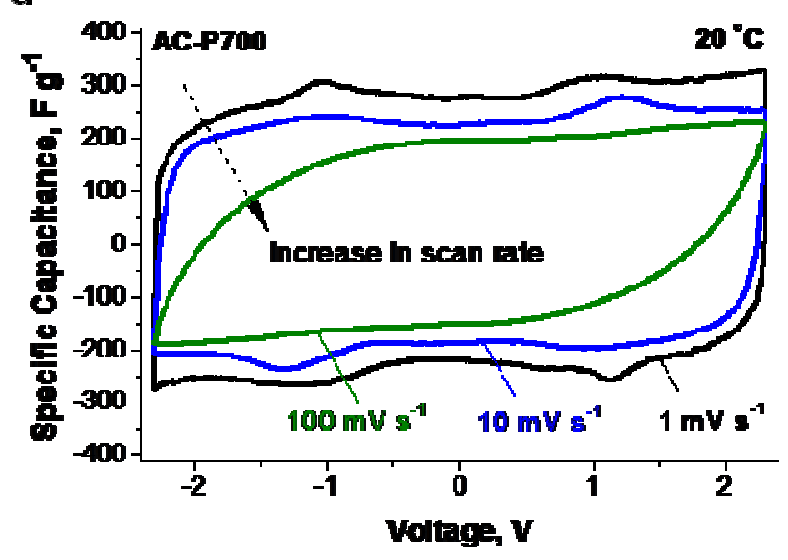

c

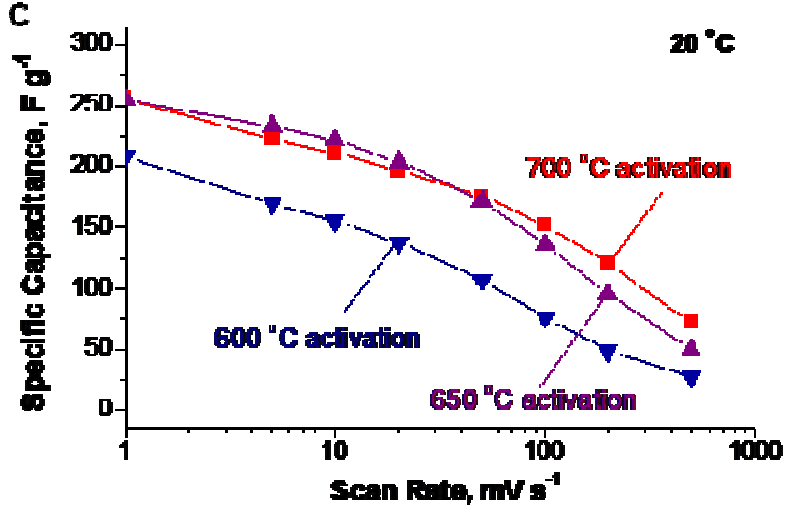

b

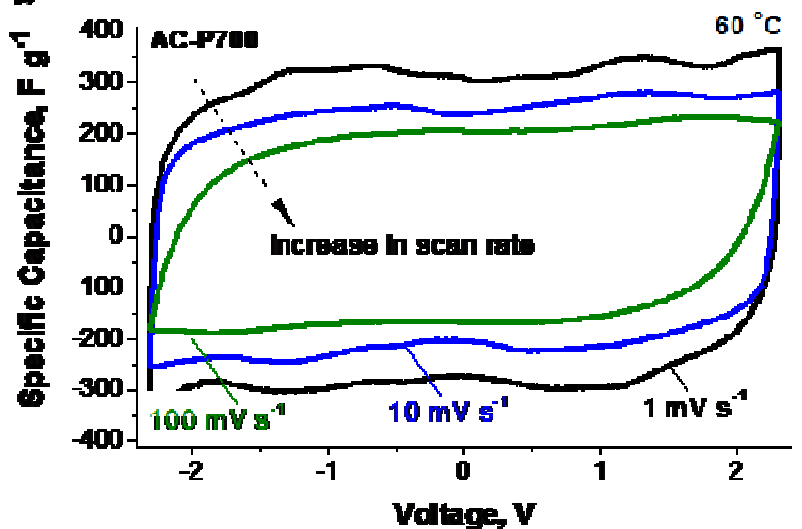

d

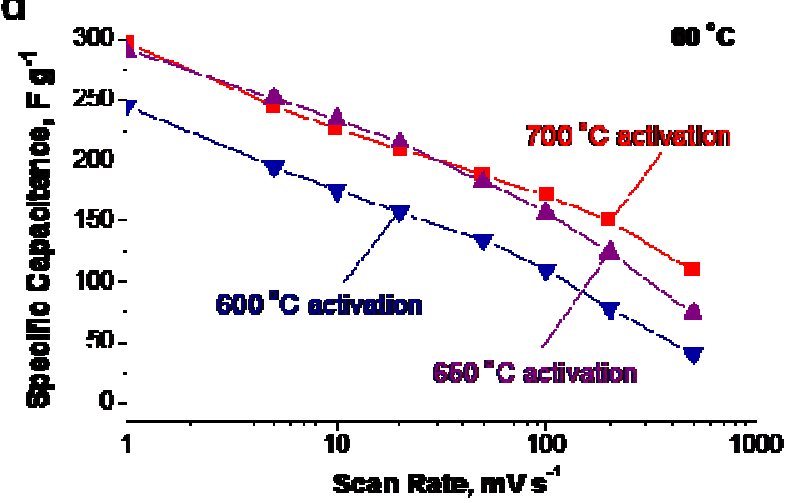

Figure 3. Electrochemical characterization of polypyrrole-derived AC materials in EMImBF4 (1-ethyl-3-methylimidazolium tetrafluoroborate) ionic liquid at room temperature $\left(20^{\circ} \mathrm{C}\right)$ and at $\left.60^{\circ} \mathrm{C}: \mathrm{a}, \mathrm{b}\right)$ cyclic voltammograms of carbon activated at $700{ }^{\circ} \mathrm{C}$ and c, d) specific capacitance of the carbons activated at three different temperatures as a function of scan rates.

The most impressive result of our studies was the discovery of the enormously high specific capacitance of the present activated carbons. The obtained capacitance values (up to $256 \mathrm{~F} \mathrm{~g}^{-}$ ${ }^{1}$ at $20{ }^{\circ} \mathrm{C}$ and above $300 \mathrm{~F} \mathrm{~g}^{-1}$ at $60^{\circ} \mathrm{C}$ ) are unmatched by the current technology and exceed by $100-200 \%$ the capacitance of conventionally produced activated carbons ${ }^{[41]}$ and by over $50 \%$ the capacitance of templated CDC with a total pore volume and pore size distribution similar to that of our samples ${ }^{[20]}$ (all obtained with the same electrolyte). The very high SSA of the produced samples (Table 1) is unlikely to be the single origin of their outstanding performance. In fact, the SSAnormalized capacitances for our samples calculated at the 1 $\mathrm{mV} \mathrm{s}^{-1}$ rate were in the range of 7.6-13.2 $\mu \mathrm{F} \mathrm{cm}$ (for ACP700) to 10-14.4 $\mu \mathrm{F} \mathrm{cm}^{-2}$ (for AC-P600) (Figure S2, Supporting Information, SI), which is noticeably higher than the 7.3 $\mu \mathrm{F} \mathrm{cm}{ }^{-2}$ previously observed with templated mesoporous CDC 20 . Because both the pore size distribution and the volume of sub-nm pores in our samples is comparable to that of mesoporous $\mathrm{CDC}^{[20]}$ and the observed pseudocapacitive peaks are relatively small (Figure 3a,b), the noticeably higher specific capacitance of polypyrrole-derived activated carbons may emphasize the importance of the carbon defects-electrolyte interactions for the capacitance enhancement, as previously observed in both organic $\left.{ }^{[21,25}\right]$ and aqueous ${ }^{[49]}$ electrolytes. By studying strictly microporous CDC in ILs, ${ }^{[18]}$ Largeot et al. observed that decreasing the CDC synthesis temperature from 1000 to $550{ }^{\circ} \mathrm{C}$ and simultaneously decreasing the average pore size from 1.1 to $0.7 \mathrm{~nm}$ resulted in the significant increase of the SSA-normalized capacitance from $\sim 7$ to $13.4 \mu \mathrm{F}$ $\mathrm{cm}^{-2}$. The authors suggested that the optimum pore size should 
mirror the ion size for the most efficient adsorption ${ }^{18}$ and that larger than optimum pores should reduce the gravimetric capacitance. ${ }^{[18]}$ They ignored, however, the effect of synthesis temperature on the microstructural changes in carbon. Our studies clearly demonstrate that SSA-normalized capacitance in excess of $14.4 \mu \mathrm{F} \mathrm{cm}$ can be achieved in largely mesoporous materials with the average pore size of $\sim 2 \mathrm{~nm}$ (Figure 1). Therefore, the presence of high volume of sub-nm pores, which may slow down the ion diffusion rate, ${ }^{[20]}$ is not needed for high energy storage characteristics of EDLC based on ILs.

The higher capacitance achieved at higher testing temperatures (compare Figure $3 \mathrm{c}$ and $3 \mathrm{~d}$ ) is likely related to the reduction in the viscosity of $\mathrm{EMImBF}_{4}$ from $34 \mathrm{cP}$ at room temperature to $12.7 \mathrm{cP}$ at $60{ }^{\circ} \mathrm{C}$ and the increase in its ionic conductivity from $12.0 \mathrm{mS} \mathrm{cm}^{-1}$ at room temperature to $39.6 \mathrm{mS} \mathrm{cm}^{-1}$ at $60{ }^{\circ} \mathrm{C}$.
The Nyquist plots of AC-P700 and AC-P650 (Figure 4 a, b) exhibit the typical features of porous electrodes with a relatively short $45^{\circ}$ Warburg region at high-medium frequencies, and an almost vertical line at low frequencies, where the behaviors become mainly capacitive. The $45^{\circ}$ segment in the Nyquist plot is related to the diffusion of the ions into the bulk of electrode particles. The decreased length of these segments was observed when the temperature was increased from 20 to $60{ }^{\circ} \mathrm{C}$ (compare Figure 5a and $\mathrm{b}$ ), indicating reduced resistance encountered by the ions during their transport into the particle core at higher temperatures. Sample AC-P600 showed the largest deviation from the ideal behavior and the largest ionic resistance (Figure $5 \mathrm{a}, \mathrm{b}$ ), suggesting that an activation temperature of $600{ }^{\circ} \mathrm{C}$ is not sufficient to achieve the welldeveloped porosity required for fast IL ion diffusion. a
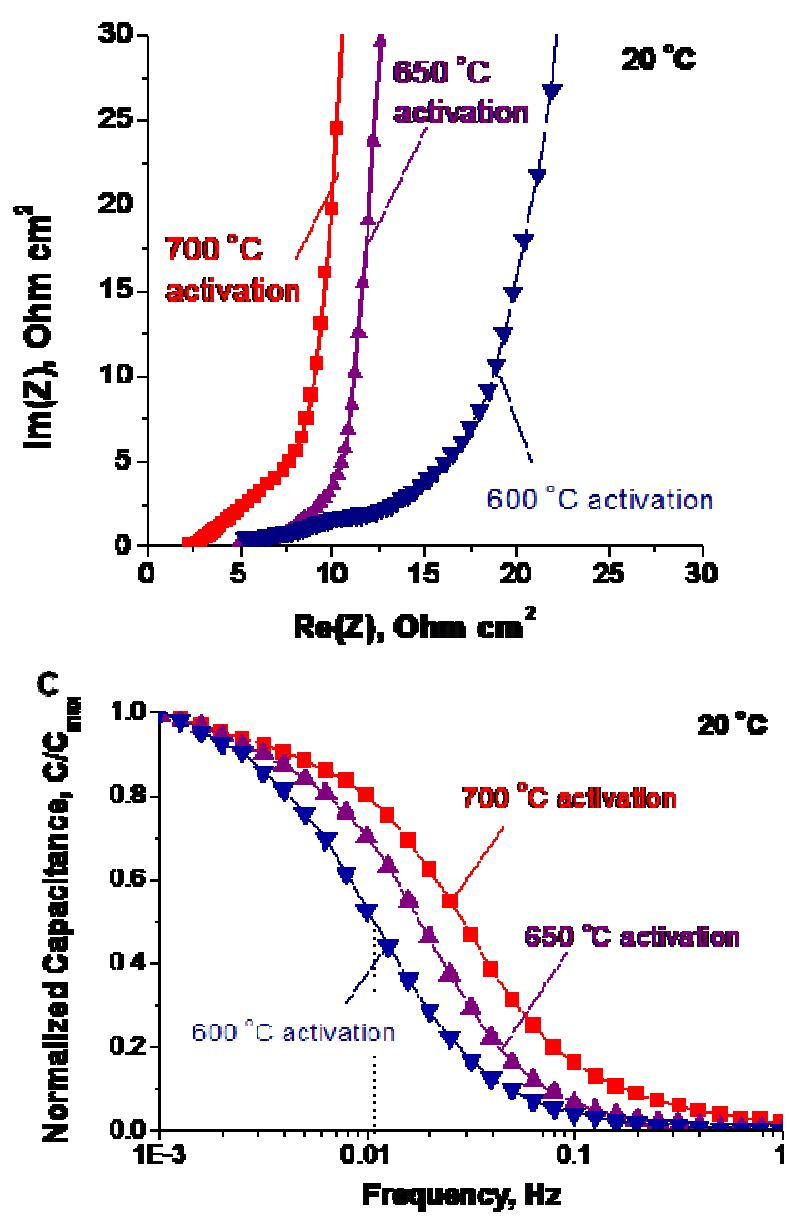
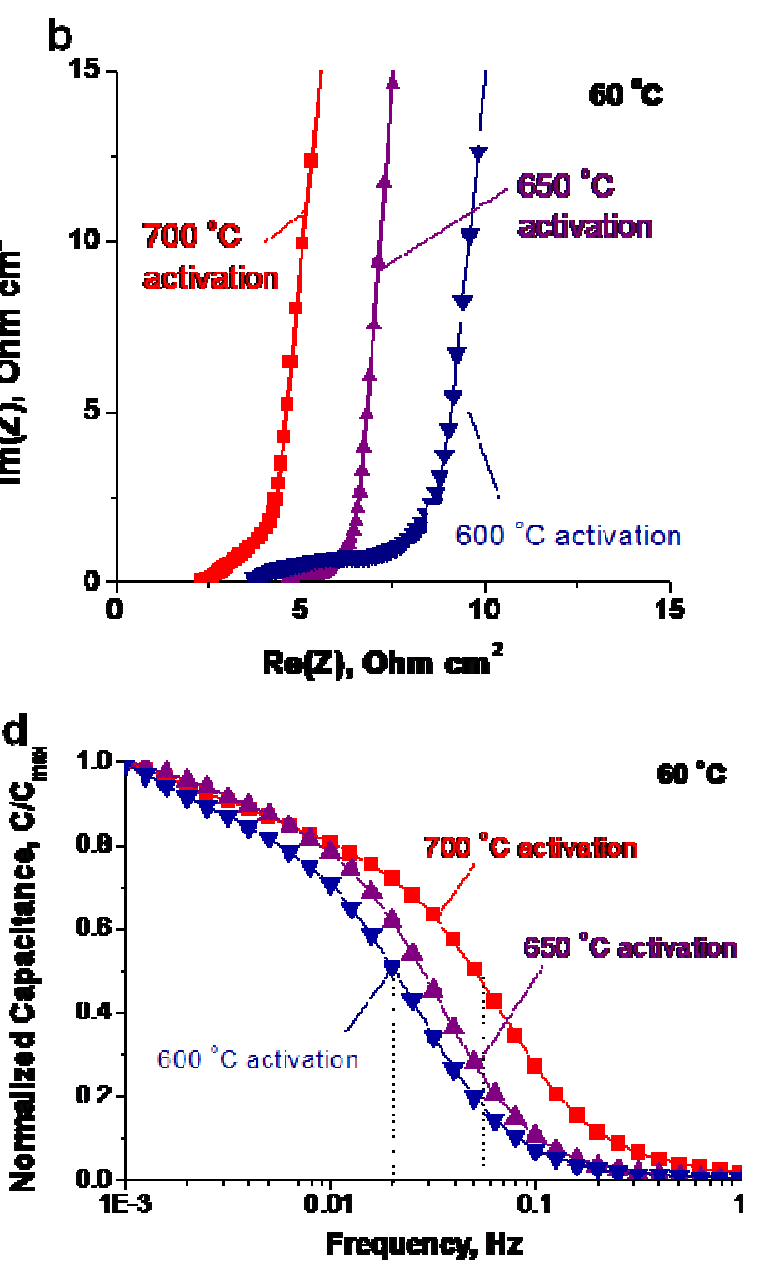

Figure 4. Electrochemical characterization of polypyrrole-derived activated carbon materials activated at various temperatures measured in $\mathrm{EMImBF}_{4}$ ionic liquid at room temperature $\left(20^{\circ} \mathrm{C}\right)$ and at $60^{\circ} \mathrm{C}:(\mathrm{a}, \mathrm{b})$ Nyquist plots, $(\mathrm{c}, \mathrm{d})$ frequency response. 
a

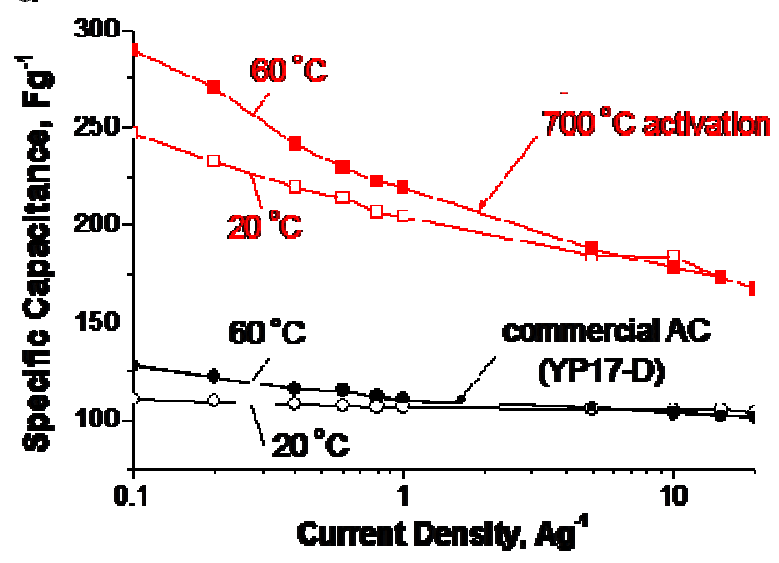

b

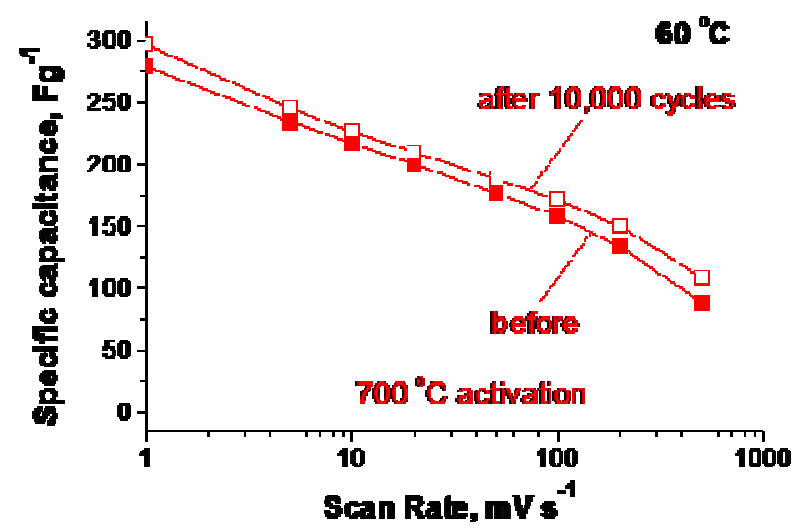

Figure 5. Electrochemical characterization of polypyrrole-derived activated carbon activated at $700{ }^{\circ} \mathrm{C}$ in $\mathrm{EMImBF}_{4}$ ionic liquid: (a) capacitance retention with current density at room temperature $\left(20^{\circ} \mathrm{C}\right)$ and at $60^{\circ} \mathrm{C}$ compared to that of commercially available activated carbon YP17-D, (b) capacitance retention/improvement after 10,000 galvanostatic charge-discharged cycles.

The performance of EDLCs in real applications is primarily determined by their charge-discharge (C-D) characteristics, which reveal their energy and power performance. Figure 5a summarizes the effect of the increasing current loads (from $100 \mathrm{~mA} \mathrm{~g}^{-1}$ to $20 \mathrm{~A} \mathrm{~g}^{-1}$ ) in galvanostatic charge-discharge tests on the specific capacitance of the most promising carbon electrode sample, AC-P700. An ideal EDLC with an infinitely fast ion transport should deliver the same energy at virtually any current density. The experimentally observed decrease of capacitance at higher current (most visible in a logarithmic scale, Figure 5a) is generally attributed to the resistance of ions traveling within the nanopores and interacting with carbon functional groups and defects. In spite of the large particle size, AC-P700 electrode showed only a moderate decrease in capacitance from 290 to $167 \mathrm{~F} \mathrm{~g} \mathrm{~g}^{-1}$ at $60{ }^{\circ} \mathrm{C}$ when the current density was increased to ultra-high value of $20 \mathrm{~A} \mathrm{~g}^{-1}$. While we expect to achieve significantly better performance with particle size and electrode thickness reduction, the obtained results are already noticeably superior than that of recently reported high-capacitance mesoporous carbons prepared using more traditional synthesis routes. For example, the mesoporous carbons produced by conventional pyrolysis and activation of citrates ${ }^{[50]}$ showed an impressive specific capacitance approaching $180 \mathrm{~F} \mathrm{~g}^{-1}$ in $\mathrm{EMImBF}_{4}$ at $60^{\circ} \mathrm{C}$ at the low- est current density. However, this capacitance dropped to below $50 \mathrm{~F} \mathrm{~g}^{-1}$ as the current density increased to $10 \mathrm{~A} \mathrm{~g}^{-1}$. In another interesting study on EDLCs employing IL electrolytes, ${ }^{[51]}$ mesoporous AC fibers were found to exhibit a specific capacitance approaching $196 \mathrm{~F} \mathrm{~g}^{-1}$ at an ultra-low current density, but only $100 \mathrm{~F} \mathrm{~g}^{-1}$ at a slightly higher but still very moderate current density of $0.5 \mathrm{~A} \mathrm{~g}^{-1}$. Even templated CDC ${ }^{[20]}$ with sub-mm particle size and straight, aligned mesopores demonstrated a reduction of its capacitance from their maximum value of $140-170 \mathrm{~F} \mathrm{~g}^{-1}$ to only $20-60 \mathrm{~F} \mathrm{~g}^{-1}$ when the current density approached $20 \mathrm{~A} \mathrm{~g}^{-1}$. A commercial activated carbon, YP-17D, optimized for use in high-power supercapacitor applications exhibited promising capacitance retention, but suffered from significantly lower capacitance values (Figure 5a). To the best of our knowledge the achieved carbon capacitance values at both small $\left(0.1 \mathrm{~A} \mathrm{~g} \mathrm{~g}^{-1}\right)$ and large $\left(20 \mathrm{~A} \mathrm{~g}^{-1}\right)$ current densities are unprecedented for IL electrolytes.

We would like to emphasize that in spite of the redox reactions evidently present (Figure 3a, b), all the assembled EDLC devices demonstrated outstanding cycle stability. In fact, after 10,000 charge-discharge galvanostatic cycles between 0 and $2.3 \mathrm{~V}$ performed at $60^{\circ} \mathrm{C}$ at a very high current density of 10 $\mathrm{A} \mathrm{g}^{-1}$, the specific capacitances of the electrodes commonly increased by $5-8 \%$ of their original values (Figure $5 \mathrm{~b}$ ), indicating excellent cycle stability of the polypyrrole-derived activated carbon $\mathrm{AC}-\mathrm{EMIBF}_{4}$ electrochemical system. Moreover, when the EDLC devices were tested in higher potential ranges $(2.3-3 \mathrm{~V})$, the CV curves still preserved rectangular shape. The typical C-D profiles remained linear (Figure S4b, Supporting Information) and the IR drop (linked to the ESR) at a high current density of $1 \mathrm{~A}$ g- 1 remained moderately small. These experiments demonstrate the PPy-based AC electrodes in an EMImBF4 electrolyte to posses stable capacitive performance in a wide electrochemical window and to offer safe and stable operation at $60{ }^{\circ} \mathrm{C}$.

\section{CONCLUSIONS}

In conclusion, we have reported a novel promising approach to produce porous carbons from synthetic polymer precursors for use in advanced EDLC systems. Synthesis of polypyrrole at room temperature followed by activation at $600-700{ }^{\circ} \mathrm{C}$ allowed us to produce porous carbons exhibiting pore volume in the range of 1.1-2.39 $\mathrm{cm}^{3} \mathrm{~g}^{-1}$ and BET surface area in the range of 2095-3432 $\mathrm{m}^{2} \mathrm{~g}^{-1}$. Activation at higher temperatures lead to increase in the surface area of the carbons and the broadening of the pore size distribution through the formation of additional volume of 1-4 nm pores. When tested in a symmetric EDLC configuration with an EMImBF4 ionic liquid electrolyte, the synthesized carbons demonstrated specific capacitance of up to $300 \mathrm{~F} \mathrm{~g}^{-1}$, which is more than a two-fold improvement compared to state-of-the-art commercial carbons and other recently reported novel carbon materials. Chargedischarge tests on the assembled EDLCs performed at $60{ }^{\circ} \mathrm{C}$ showed no visible degradation and even small (up to $8 \%$ ) increase in the specific capacitance after 10000 galvanostatic cycles. Very good rate performance at high scan rates and current densities suggested a great promise of the proposed technology for safe and high-energy EDLC applications. 


\section{EXPERIMENTAL SECTION}

Activated Carbon Preparation. Polypyrrole (PPy) is a conducting polymer formed from a number of connected pyrrole ring structures. The polypyrrole was prepared as follows; $3 \mathrm{~g}$ of pyrrole (recently distilled under nitrogen) was added to $200 \mathrm{~mL}$ of $0.5 \mathrm{M} \mathrm{FeCl}_{3}$ solution and the mixture was magnetically stirred for $2 \mathrm{~h}$. The generated polypyrrole was recovered by filtration, thoroughly washed with distilled water and dried. The dry polypyrrole was then activated by heating (at a ramp rate of $3{ }^{\circ} \mathrm{C} / \mathrm{min}$ ) a $\mathrm{KOH} / \mathrm{PPy}$ mixture (at $\mathrm{KOH} / \mathrm{PPy}$ weight ratio of 4 ) under nitrogen to a final temperature of 600 , 650 or $700{ }^{\circ} \mathrm{C}$ for $1 \mathrm{~h}$. The activated carbons were then thoroughly washed with $10 \mathrm{wt} \% \mathrm{HCl}$ to remove any inorganic salts, and then with distilled water until neutral $\mathrm{pH}$ and finally dried in an oven $\left(120^{\circ} \mathrm{C}\right)$.

Carbon Characterization. The morphology of the prepared carbon materials was observed via a Leo 1530 (LEO, Osaka, Japan, now Nano Technology Systems Division of Carl Zeiss SMT, USA) scanning electron microscope (SEM). TEM observations of the AC microstructure were carried out using a Philips CM200UT microscope (Philips, Netherlands). Nitrogen sorption isotherms of the carbon samples were collected at $-196{ }^{\circ} \mathrm{C}$ using a Micromeritics ASAP 2020 sorptometer. The surface area was calculated using the BET method based on adsorption data in the relative pressure $\left(\mathrm{P} / \mathrm{P}_{0}\right)$ range 0.06 to 0.14 and total pore volume was determined from the amount of nitrogen adsorbed at a relative pressure $\left(\mathrm{P} / \mathrm{P}_{0}\right)$ of 0.99 . The pore size distribution (PSD) was determined via a Non Local Density Functional Theory (NLDFT) method using nitrogen adsorption data, and assuming a slit pore model. The Raman spectra were recorded using a Nicolet Almega XR Micro and Macro Raman Analysis System (Thermo Fisher Scientific Inc., USA). The source of radiation was laser operating at a wavelength of $488 \mathrm{~nm}$ and sample exposure time of 5 mins.

Device Assembly. Electrodes were prepared by mixing 94 $\mathrm{wt} \%$ carbon samples and $6 \mathrm{wt} \%$ polytetrafluoroethylene (PTFE) in ethanol to form a slurry. The slurry was stirred uniformly and heated at the same time on a hot plate at $150{ }^{\circ} \mathrm{C}$ to evaporate most of the ethanol and form a plasticine-like material. The resulting AC-PTFE composite was then rolled to $\sim 300 \mu \mathrm{m}$ thick electrode. The electrode was placed into a vacuum oven $\left(100{ }^{\circ} \mathrm{C}\right)$ overnight to remove moisture and residual hydrocarbons, and then was cut into a circular shape with diameter of 1/2 inch for EDLC electrodes. 2016 stainlesssteel coin cells with two symmetrical carbon electrodes separated by two GORE ${ }^{\mathrm{TM}}$ PTFE separators (W.L Gore and Associates, USA) of $\sim 25 \mu \mathrm{m}$ in thickness and $\sim 60 \%$ porosity were assembled inside an Ar-filled glove box $(<1 \mathrm{ppm}$ of oxygen and $\mathrm{H}_{2} \mathrm{O}$, Innovation Technology, USA). Al foil of $300 \mu \mathrm{m}$ in thickness roughened using a 600 grit $\mathrm{SiC}$ sandpaper and coated by a thin layer ( $\sim 10$ to $20 \mu \mathrm{m})$ of carbon coating (BW 525 , Superior Graphite, USA) was attached to each electrode and served as current collector. Carbon coating was used to reduce the interfacial resistance between the electrode and the current collector. Ionic liquid $\mathrm{EMImBF}_{4}$ (purity $>98 \%$, Ionic Liquids Technology, Germany) was selected as electrolyte because of its high dielectrical permittivity combined with relatively high ionic conductivity and low viscosity at $<60{ }^{\circ} \mathrm{C}$.

Electrochemical Testing. Cyclic voltammetry (CV) studies were performed using a Solartron 1480A MultiStat (Solartron Analytical, UK) in the voltage range $-2.3 \mathrm{~V}$ to $+2.3 \mathrm{~V}$ and in scan rates from 1 to $1000 \mathrm{mV} \mathrm{s}^{-1}$. The gravimetric capacitance, $\mathrm{C}\left(\mathrm{F} \mathrm{g}^{-1}\right)$, was calculated according to

$$
C=\frac{2 I}{(d V / d t) m}
$$

where $I$ is the current (A), $d V / d t$ is the scan rate $\left(\mathrm{V} \mathrm{s}^{-1}\right)$, and $m$ is the mass (grams) of carbon in each electrode.

Electrochemical impedance spectroscopy (EIS) measurements were carried out using a Gamry Reference $600^{\mathrm{TM}}$ Potentiostat/Galvanostat/ZRA (Gamry Instruments, Inc., USA) in the frequency range of $1 \mathrm{mHz}-100 \mathrm{kHz}$ with a $10 \mathrm{mV}$ $\mathrm{AC}$ amplitude. The gravimetric capacitance, $\mathrm{C}\left(\mathrm{F} \mathrm{g}^{-1}\right)$, was calculated according to

$$
C=\frac{2 \cdot|\operatorname{Im}(Z)|}{2 \pi f \cdot\left[(\operatorname{Im}(Z))^{2}+(\operatorname{Re}(Z))^{2}\right] m}
$$

where $f$ is the operating frequency $(\mathrm{Hz}), \operatorname{Im}(Z)$ and $\operatorname{Re}(Z)$ are the imaginary and real parts of the total device resistance $(\mathrm{Ohm})$, and $m$ is the mass (grams) of carbon in each electrode.

Galvanostatic charge-discharge cycle tests (GC) were measured using an Arbin BT-2000 testing system (Arbin Instruments, USA) in the voltage range $0-2.3 \mathrm{~V}$ and at chargedischarge current densities between 0.1 and $20 \mathrm{~A} \mathrm{~g}^{-1}$, based on the mass of a single electrode. The gravimetric capacitance, $\mathrm{C}$ $\left(\mathrm{F} \mathrm{g}^{-1}\right)$, was calculated according to

$$
C=\frac{2 I}{(d V / d t) m}
$$

where $I$ is the current (A), $d V / d t$ is the slope of the discharge curve $\left(\mathrm{V} \mathrm{s}^{-1}\right)$, and $m$ is the mass (grams) of carbon in each electrode.

To perform high temperature electrochemical testing, the model capacitors were kept at $60{ }^{\circ} \mathrm{C}$ using an environmental test chamber (Tenney Enviromental, Thermal Products Solutions, USA).

\section{Supporting Information}

Supporting Information is available from the Wiley Online Library or from the author.

\section{ACKNOWLEDGMENTS}

This work was partially supported by the AFOSR under grant \# FA9550-09-1-0176. M.S. acknowledges the assistance of the Spanish MICINN for the award of a postdoctoral mobility contract.

\section{REFERENCES}

(1) Conway, B. E. Electrochemical Supercapacitors: Scientific Fundamentals and Technological Applications; Kluwer Academic/Plenum Publishers: New York, USA, 1999.

(2) Simon, P.; Gogotsi, Y. Nature Materials 2008, 7, 845.

(3) Pech, D.; Brunet, M.; Durou, H.; Huang, P. H.; Mochalin, V.; Gogotsi, Y.; Taberna, P. L.; Simon, P. Nature Nanotechnology 2010, 5, 651 .

(4) Chmiola, J.; Largeot, C.; Taberna, P. L.; Simon, P.; Gogotsi, Y. Science 2010, 328, 480. 
(5) Chmiola, J.; Yushin, G.; Gogotsi, Y.; Portet, C.; Simon, P. Science 2006, 313, 1760.

(6) Miller, J. R.; Outlaw, R. A.; Holloway, B. C. Science 2010, 329, 1637.

(7) Zhu, Y.; Murali, S.; Stoller, M. D.; Ganesh, K. J.; Cai, W.; Ferreira, P. J.; Pirkle, A.; Wallace, R. M.; Cychosz, K. A.; Thommes, M.; Su, D.; Stach, E. A.; Ruoff, R. S. Science 2011.

(8) Kovalenko, I.; Bucknall, D.; Yushin, G. Adv. Funct. Mater. 2010, DOI: 10.1002/adfm.201000906.

(9) Kyotani, T.; Ma, Z. X.; Tomita, A. Carbon 2003, 41, 1451.

(10) Kajdos, A.; Kvit, A.; Jones, F.; Jagiello, J.; Yushin, G. J.

Am. Chem. Soc. 2010, 132, 3252.

(11) Portet, C.; Yang, Z.; Korenblit, Y.; Gogotsi, Y.; Mokaya, R.; Yushin, G. J. Electrochem. Soc. 2009, 156, A1.

(12) Ania, C. O.; Khomenko, V.; Raymundo-Pinero, E.; Parra, J. B.; Beguin, F. Adv. Funct. Mater. 2007, 17, 1828.

(13) Korenblit, Y.; Kajdos, A.; West, W. C.; Smart, M. C.; Brandon, E. J.; Kvit, A.; Jagiello, J.; Yushin, G. Adv. Funct. Mater. 2011, in review.

(14) Yushin, G.; Dash, R. K.; Gogotsi, Y.; Jagiello, J.; Fischer, J. E. Adv. Funct. Mater. 2006, 16, 2288.

(15) Hoffman, E. N.; Yushin, G.; El-Raghy, T.; Gogotsi, Y.; Barsoum, M. W. Microporous Mesoporous Mater. 2008, 112, 526.

(16) Yushin, G.; Hoffman, E.; Barsoum, M. W.; Gogotsi, Y.; Howell, C. A.; Sandeman, S. R.; Phillips, G. J.; Lloyd, A. W.; Mikhalovsky, S. V. Biomaterials 2006, 27, 5755.

(17) Janes, A.; Permann, L.; Arulepp, M.; Lust, E. Electrochem. Commun. 2004, 6, 313.

(18) Largeot, C.; Portet, C.; Chmiola, J.; Taberna, P. L.; Gogotsi, Y.; Simon, P. JACS 2008, 130, 2730.

(19) Portet, C.; Yushin, G.; Gogotsi, Y. J. Electrochem. Soc 2008, 155 (7), A531.

(20) Rose, M.; Korenblit, Y.; Kockrick, E.; Borchardt, L.; Oschatz, M.; Kaskel, S.; Yushin, G. In Small 2011; Vol. 7, p 1108 .

(21) Korenblit, Y.; Rose, M.; Kockrick, E.; Borchardt, L.; Kvit, A.; Kaskel, S.; Yushin, G. Acs Nano 2010, 4, 1337.

(22) Raymundo-Piñero, E.; Kierzek, K.; Machnikowski, J.; Béguin, F. Carbon 2006, 44, 2498.

(23) Huang, J. S.; Sumpter, B. G.; Meunier, V. Angewandte Chemie-International Edition 2008, 47, 520.

(24) Huang, J. S.; Sumpter, B. G.; Meunier, V. Chemistry-a European Journal 2008, 14, 6614.

(25) Portet, C.; Yushin, G.; Gogotsi, Y. Carbon 2007, 45, 2511.

(26) Taberna, P. L.; Simon, P.; Fauvarque, J. F. J. Electrochem. Soc. 2003, 150, A292.

(27) Gamby, J.; Taberna, P. L.; Simon, P.; Fauvarque, J. F.; Chesneau, M. Journal of Power Sources 2001, 101, 109.
(28) Frackowiak, E.; Beguin, F. Carbon 2001, 39, 937.

(29) Hulicova-Jurcakova, D.; Seredych, M.; Lu, G. Q.; Bandosz, T. J. Adv. Funct. Mater. 2009, 19, 438.

(30) Raymundo-Pinero, E.; Cadek, M.; Beguin, F. Adv. Funct. Mater. 2009, 19, 1032.

(31) Hulicova-Jurcakova, D.; Kodama, M.; Shiraishi, S.; Hatori, H.; Zhu, Z. H.; Lu, G. Q. Adv. Funct. Mater. 2009, 19, 1800.

(32) Wei, L.; Sevilla, M.; Fuertesc, A. B.; Mokaya, R.; Yushin, G. Advanced Energy Materials 2011, 1, 356.

(33) Liang, Y. Y.; Schwab, M. G.; Zhi, L. J.; Mugnaioli, E.; Kolb, U.; Feng, X. L.; Mullen, K. JACS 2010, 132, 15030.

(34) Hu, B.; Wang, K.; Wu, L. H.; Yu, S. H.; Antonietti, M.; Titirici, M. M. Adv. Mater. 2010, 22, 813.

(35) Titirici, M. M.; Antonietti, M. Chem. Soc. Rev. 2010, $39,103$.

(36) Sevilla, M.; Fuertes, A. B. Chemistry-a European Journal 2009, 15, 4195.

(37) Sevilla, M.; Fuertes, A. B. Carbon 2009, 47, 2281.

(38) Borodin, O.; Smith, G. D. J. Phys. Chem. B 2006, 110, 11481.

(39) Balducci, A.; Dugas, R.; Taberna, P. L.; Simon, P.; Plee, D.; Mastragostino, M.; Passerini, S. J. Power Sources 2007, 165,922

(40) Kurig, H.; Janes, A.; Lust, E. J. Electrochem. Soc. 2010, 157, A272.

(41) Wei, L.; Yushin, G. Power Sources 2011, 1964072

(42) Brunauer, S.; Emmett, P.; Teller, E. J. of Am. Chem. Soc. 1938, 60, 309

(43) Z.G. Cambaz; G.N. Yushin; K.L. Vyshnyakova; L.N. Pereselentseva; Gogotsi, Y. G. J. Am. Ceram. Soc 2006, 89, 509.

(44) Nemanich, R. J.; Lukovsky, G.; Solin, S. A. In In Proc. Int. Conf. on Lattice Dynamics; Balkanski, M., Ed.; Flammarion Press: Paris, 1975, p 619.

(45) Tuinstra, F.; Koenig, J. L. J. Chem. Physics 1970, 53, 1126.

(46) Tan, P. H.; Dimovski, S.; Gogotsi, Y. Phil. Trans. oyal Soc. A 2004, 362.

(47) Thomsen, C.; Reich, S. Phys. Rev. Lett. 2000, 85, 5214.

(48) Titirici, M. M.; Thomas, A.; Antonietti, M. Advanced Functional Materials 2007, 17, 1010.

(49) Gallagher, K. G.; Yushin, G.; Fuller, T. F. J. Electrochem. Soc. 2010, 157, B820.

(50) Zhou, J.; Yuan, X.; Xing, W.; Si, W. J.; Zhuo, S. P. Carbon 2010, 48, 2765.

(51) Xu, B.; Wu, F.; Chen, R. J.; Cao, G. P.; Chen, S.; Yang, Y. S. J. Power Sources 2010, 195, 2118. 